\title{
Single photon emission-computed tomography (SPECT) for functional investigation of the proximal tubule in conscious mice
}

François Jouret, Stéphan Walrand, Kleber S. Parreira, Pierre J. Courtoy, Stanislas Pauwels, Olivier Devuyst and François Jamar

Am J Physiol Renal Physiol 298:F454-F460, 2010. First published 2 December 2009;

doi:10.1152/ajprenal.00413.2009

You might find this additional info useful...

This article cites 29 articles, 13 of which can be accessed free at:

http://ajprenal.physiology.org/content/298/2/F454.full.html\#ref-list-1

This article has been cited by 1 other HighWire hosted articles

Pynamic and Static Small-Animal SPECT in Rats for Monitoring Renal Function After ${ }^{177}$ Lu-Labeled Tyr $^{3}$-Octreotate Radionuclide Therapy

Marleen Melis, Jan de Swart, Monique de Visser, Saskia C. Berndsen, Stuart Koelewijn, Roelf

Valkema, Otto C. Boerman, Eric P. Krenning and Marion de Jong

J Nucl Med, December , 2010; 51 (12): 1962-1968.

[Abstract] [Full Text] [PDF]

Updated information and services including high resolution figures, can be found at:

http://ajprenal.physiology.org/content/298/2/F454.full.html

Additional material and information about AJP - Renal Physiology can be found at: http://www.the-aps.org/publications/ajprenal

This infomation is current as of December 20, 2011.

AJP - Renal Physiology publishes original manuscripts on a broad range of subjects relating to the kidney, urinary tract, and their respective cells and vasculature, as well as to the control of body fluid volume and composition. It is published 12 times a year (monthly) by the American Physiological Society, 9650 Rockville Pike, Bethesda MD 20814-3991. Copyright @ 2010 by the

American Physiological Society. ISSN: 0363-6127, ESSN: 1522-1466. Visit our website at http://www.the-aps.org/. 


\title{
Single photon emission-computed tomography (SPECT) for functional investigation of the proximal tubule in conscious mice
}

\author{
François Jouret, ${ }^{1 *}$ Stéphan Walrand, ${ }^{2 *}$ Kleber S. Parreira, ${ }^{1}$ Pierre J. Courtoy, ${ }^{3}$ Stanislas Pauwels, ${ }^{2}$ \\ Olivier Devuyst, ${ }^{* *}$ and François Jamar ${ }^{2 *}$ \\ ${ }^{1}$ Division of Nephrology, ${ }^{2}$ Laboratory of Molecular Imaging and Experimental Radiotherapy, and ${ }^{3}$ de Duve Institute, \\ CELL Unit, Université catholique de Louvain Medical School, Brussels, Belgium
}

Submitted 22 July 2009; accepted in final form 30 November 2009

Jouret F, Walrand S, Parreira KS, Courtoy PJ, Pauwels S, Devuyst O, Jamar F. Single photon emission-computed tomography (SPECT) for functional investigation of the proximal tubule in conscious mice. Am J Physiol Renal Physiol 298: F454-F460, 2010. First published December 2, 2009; doi:10.1152/ajprenal.00413.2009.— Noninvasive analysis of renal function in conscious mice is necessary to optimize the use of mouse models. In this study, we evaluated whether single photon emission-computed tomography (SPECT) using specific radionuclear tracers can be used to analyze changes in renal proximal tubule functions. The tracers included ${ }^{99 \mathrm{~m}} \mathrm{TC}$ - dimercaptosuccinic acid ( $\left.{ }^{99 \mathrm{~m}} \mathrm{Tc}-\mathrm{DMSA}\right)$, which is used for cortex imaging; ${ }^{99 \mathrm{~m}} \mathrm{Tc}$-mercaptoacetyltriglycine $\left({ }^{99 \mathrm{~m}} \mathrm{Tc}-\mathrm{MAG} 3\right)$, used for dynamic renography; and ${ }^{123} \mathrm{I}-\beta_{2}$-microglobulin, which monitors receptor-mediated endocytosis. ${ }^{99 \mathrm{~m}} \mathrm{Tc}-\mathrm{DMSA}$ SPECT imaging was shown to delineate the functional renal cortex with a $\sim 1-\mathrm{mm}$ spatial resolution and accumulated in the cortex reaching a plateau $5 \mathrm{~h}$ after injection. The cortical uptake of ${ }^{99 \mathrm{~m}}$ Tc-DMSA was abolished in Clcn 5 knockout mice, a model of proximal tubule dysfunction. Dynamic renography with ${ }^{99 \mathrm{~m}} \mathrm{Tc}-\mathrm{MAG} 3$ in conscious mice demonstrated rapid extraction from blood, renal accumulation, and subsequent tubular secretion. Anesthesia induced a significant delay in the ${ }^{99 \mathrm{~m}} \mathrm{Tc}-\mathrm{MAG} 3$ clearance. The tubular reabsorption of ${ }^{123} \mathrm{I}-\beta_{2}$-microglobulin was strongly impaired in the Clcn5 knockout mice, with defective tubular processing and loss of the native tracer in urine, reflecting proximal tubule dysfunction. Longitudinal studies in a model of cisplatin-induced acute tubular injury revealed a correlation between tubular recovery and ${ }^{123} \mathrm{I}-\beta_{2}$-microglobulin uptake. These data show that SPECT imaging with well-validated radiotracers allows in vivo investigations of specific proximal tubule functions in conscious mice.

receptor-mediated endocytosis; tubular secretion; ClC-5; Dent's disease; radionuclear tracers

TRANSGENIC MOUSE STRAINS ARE widely used to investigate the structure and function of developing and mature kidneys and to model human disorders. Thus far, functional studies into disease mechanisms essentially require animal death and ex vivo investigations that are potentially limited by various factors including low fertility rates, gender effects (e.g., X-linked transmission), or limited life span in some models. These restrictions complicate the design of intervention studies and require the development of large colonies, increasing costs and raising ethical questions. To circumvent some of these limitations, efforts are being made to develop in vivo functional imaging techniques in mice. In particular, the possibility to perform quantitative and/or dynamic molecular imaging stud-

* F. Jouret, S. Walrand, O. Devuyst, and F. Jamar contributed equally to this study.

Address for reprint requests and other correspondence: O. Devuyst, Div. of Nephrology, Université Catholique de Louvain Medical School, Ave. Hippocrate, UCL 54.30, B-1200 Brussels, Belgium (e-mail: olivier.devuyst@uclouvain.be). ies using high-resolution positron emission tomography (PET) or single photon emission-computed tomography (SPECT) has emerged recently (23).

Among its numerous applications, SPECT may be useful for noninvasive investigation of renal function in the mouse by means of dynamic imaging, parenchymal scanning, and quantification of filtration, secretion, and reabsorption events (8). In particular, the possibility to use different radiotracers for SPECT imaging provides the opportunity to investigate various transport processes taking place in the proximal tubule (PT), a segment that plays a paramount role in homeostasis (Fig. 1). Diseases causing PT dysfunction are associated with life-threatening complications, including electrolyte and acidbase disorders, protein and amino acid imbalance, as well as abnormal handling of numerous endogenous and exogenous compounds.

To evaluate the technical possibilities of dynamic molecular imaging in vivo, we have used a SPECT system (26) to investigate the transport functions of the PT including apical and basolateral uptake and apical secretion. We evaluated these parameters in control mice, mice with restricted kidney infarction, and mice with congenital or acquired PT dysfunction (renal Fanconi syndrome). In particular, we used Clcn 5 knockout $\left(\mathrm{KO} ; C l c n 5^{\mathrm{Y} /-}\right)$ mice that are characterized by generalized PT dysfunction and low-molecular-weight (LMW) proteinuria due to defective receptor-mediated endocytosis (7) and represent a well-established model for Dent's disease (28). We also used a mouse model of acquired, reversible PT injury induced by cisplatin (9) to evaluate the potential recovery over time.

To avoid the potential deleterious effects of general anesthesia, SPECT imaging was performed in conscious mice, using three well-established renal radionuclear tracers (Fig. 1). ${ }^{99} \mathrm{~m}$ Tc-mercaptoacetyltriglycine $\left({ }^{99 \mathrm{~m}} \mathrm{Tc}-\mathrm{MAG} 3\right)$, which is secreted into the urine following basolateral uptake by PT cells, is regarded as the best available tubular marker for dynamic renography (12). Dimercaptosuccinic acid ( $\left.{ }^{99 \mathrm{~m}} \mathrm{Tc}-\mathrm{DMSA}\right)$, which accumulates in the renal cortex by a basolateral uptake in the epithelial cells lining the pars recta ( $\mathrm{S} 3$ segment), is used for cortex imaging $(16,25)$. Finally, ${ }^{123} \mathrm{I}-\beta_{2}-$ microglobulin is a reference tracer for assessing the receptor mediated endocytosis of ultrafiltered LMW proteins by PT cells (7).

\section{MATERIALS AND METHODS}

Animals. Experiments were conducted on 12- to 20-wk-old C57/ BL6 (body wt: 25-30 g) and matched pairs of Clcn5 wild-type $\left(C l c n 5^{\mathrm{Y} /+}\right)$ and $\mathrm{KO}\left(\mathrm{Clcn5}^{\mathrm{Y} /-}\right)$ littermates. The $\mathrm{Clcn} 5^{\mathrm{Y} /-}$ mice have been extensively characterized (28) and had similar body weight, hematocrit, and plasma creatinine levels than wild-type littermates in this age group. Restricted kidney infarction was induced in C57 mice 


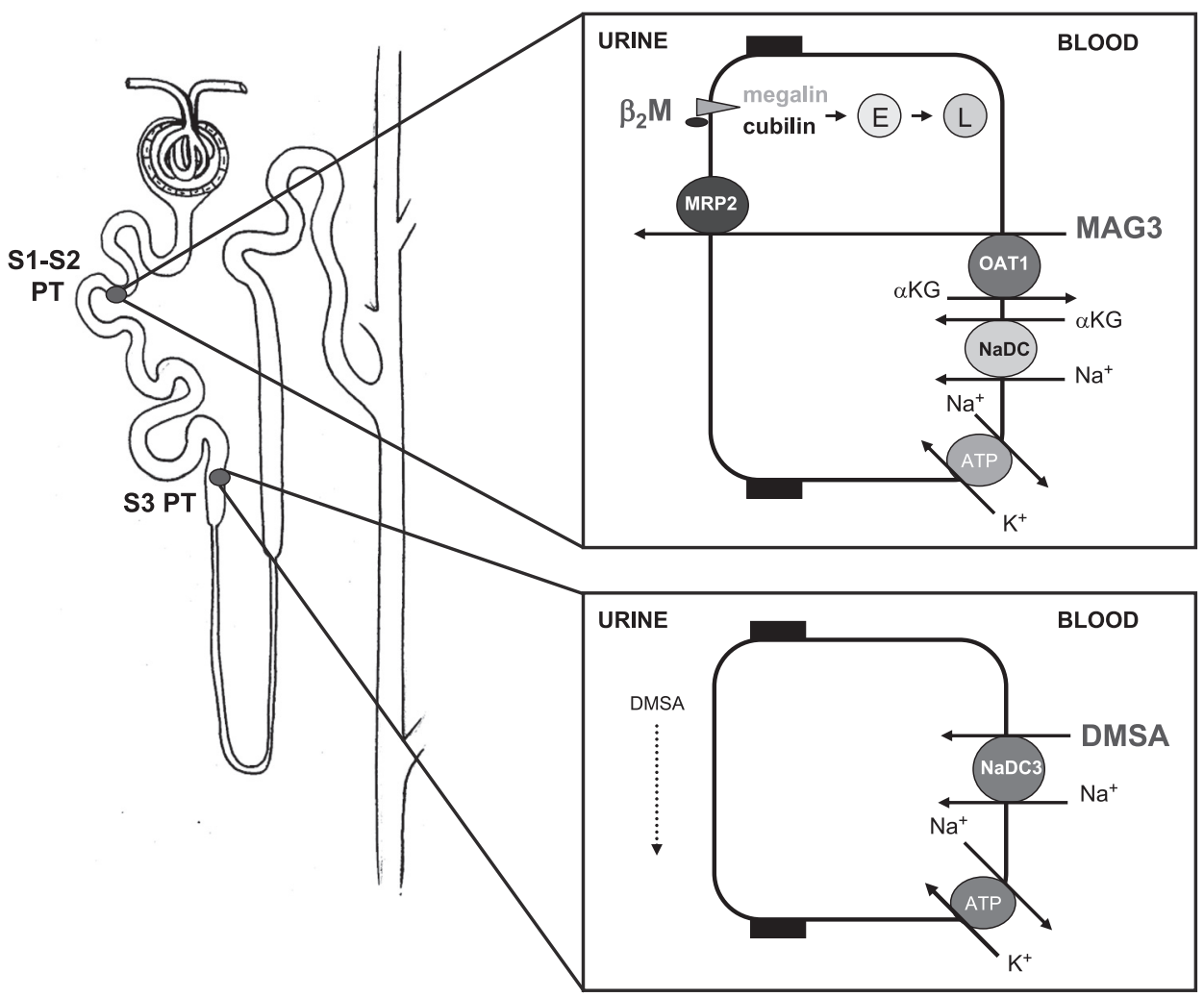

Fig. 1. Transport of $\beta_{2}$-microglobulin ( $\beta 2 \mathrm{M}$ ), mercaptoacetyltriglycine (MAG3), and dimercaptosuccinic acid (DMSA) along the proximal tubule (PT). The epithelial cells lining the convoluted part (S1-S2 segments) of the PT efficiently reabsorb the low-molecular-weight $\beta 2 \mathrm{M}$ from the primitive urine (glomerular ultrafiltrate) by receptor-mediated endocytosis after interaction with the multiligand receptors megalin and cubilin. After internalization and progression along the endocytic apparatus (E), $\beta 2 \mathrm{M}$ is degraded in lysosomes (L). In addition, PT cells secrete MAG3 from the plasma into the urine. The basolateral uptake of MAG3 occurs in exchange for intracellular dicarboxylates, namely, $\alpha$-ketoglutarate $(\alpha-\mathrm{KG})$, through the organic anion transporter OAT1 (SLC22A6). A-KG is a key intermediate in the Krebs cycle, which enters PT cells through a $\mathrm{Na}^{+}$-dicarboxylate cotransporter (NaDC; not formally identified as NaDC3; see below), whereas $\mathrm{Na}^{+}$is recycled through the $\mathrm{Na}^{+}-\mathrm{K}^{+}$-ATPase. The MAG3 secretion into the lumen is mediated by the multidrug resistance protein MRP2 inserted in the apical membrane of PT cells. The $\mathrm{Na}^{+}$-dependent phosphate transporter NPT1 may also be involved in MAG3 secretion. The epithelial cells lining the pars recta (S3 segment) of the PT are involved in the basolateral uptake of DMSA from peritubular capillaries, which is mediated by the $\mathrm{Na}^{+}$-dicarboxylate cotransporter NaDC3 (also named SLC13A3). A limited fraction of DMSA is filtered through the glomerulus and lost in the urine. Modified from Refs. 4 and 24.

by clamping the superior pole of the organ for 30 min under anesthesia. A model of partial or full recovery of acute PT injury was obtained by a single injection of either vehicle (saline) or cisplatin (12 $\mathrm{mg} / \mathrm{kg} \mathrm{BW}$ ip) in C57 mice with follow-up for $2 \mathrm{wk}$ (9). Mice were housed individually in metabolic cages to assess overnight urine flow rate and renal function during the cisplatin protocol. All procedures were performed in accordance with National Institutes of Health guidelines for the care and use of laboratory animals, and with the approval of the Committee for Animal Rights of the Université catholique de Louvain Medical School.

Radiotracers. Human $\beta_{2}$-microglobulin ( $\beta 2 \mathrm{M}$; Sigma, St. Louis, MO) was iodinated with ${ }^{123} \mathrm{I}_{-} \mathrm{Na}^{+}$(GE Healthcare, Brussels, Belgium) and Iodobeads (Pierce, Aalst, Belgium) as previously described (7) (purity in excess of $92 \%$ trichloroacetic acid-precipitable). Dimercaptosuccinic acid (TechneScan DMSA) or mercaptoacetyltriglycine (TechneScan MAG3) from Tyco HealthCare (Mechelen, Belgium) were radiolabeled with ${ }^{99 \mathrm{~m}} \mathrm{Tc}-\mathrm{Na}$-pertechnetate (Tyco HealthCare) following the standard procedure. The physical half-life of ${ }^{123} \mathrm{I}$ is 13 $\mathrm{h}$ and that of ${ }^{99 \mathrm{~m}} \mathrm{Tc}$ is $6 \mathrm{~h}$. Radiopharmaceutical purity was $>99 \%$, as confirmed by instant thin-layer chromatography. All radiotracers were diluted in saline $(\mathrm{NaCl} 0.9 \%)$ and injected (lateral caudal vein of the tail iv) in a total volume of $150 \mu \mathrm{l}$.

SPECT system. The small-animal SPECT device (Linoview Systems, Amsterdam, The Netherlands) is made of four $\gamma$-detectors based on pixilated $\mathrm{CsI}(\mathrm{Na})$ scintillators $(5-\mathrm{mm}$ thickness, $2.44 \times 2.44-\mathrm{mm}$ crystal size). Detectors are fitted with a rake collimator equipped with an adjustable slit aperture, made of two iridium square rods $(2 \times 2 \times$ 60-mm) (Supplemental Fig. 1; all supplementary material for this article is available on the journal web site). The spatial resolution of the system after reconstruction is $0.35 \mathrm{~mm}$ (26).

Acquisition procedure. In a preliminary experiment, dynamic ${ }^{99 \mathrm{~m}}$ Tc-MAG3 SPECT imaging was performed before and after anesthesia (ketamine, $100 \mu \mathrm{g} / \mathrm{g}$, Merial, Brussels, Belgium; xylazine 10 $\mu \mathrm{g} / \mathrm{g}$, Bayer, Antwerp, Belgium) in two pairs of C57 mice. Subsequently, kinetic studies with the three radiotracers were performed on conscious $\mathrm{Clcn} 5$ mice placed in a plastic holder to reduce animal motion during imaging (Supplemental Fig. 1). The mice (pairs of Clcn5 WT vs. KO) were studied over a total period of $8 \mathrm{wk}$, with three sequential injections of DMSA, MAG3, and $\beta 2 \mathrm{M}$ on the same mice, separated by a minimal interval of 5 days.

Static SPECT was obtained hourly (acquisitions of $5 \mathrm{~min}$ each) during $5 \mathrm{~h}$ after intravenous (iv) injection of $700 \mu \mathrm{Ci}$ of ${ }^{99 \mathrm{~m}} \mathrm{Tc}-\mathrm{DMSA}$ ( $n=4$ pairs). At $6 \mathrm{~h}$ postinjection, a 30-min acquisition was performed under anesthesia to obtain high-resolution images. In two pairs of mice, the scanning was repeated $30 \mathrm{~min}$ after furosemide injection $(10 \mathrm{mg} / \mathrm{kg}$ BW ip; final volume: $30 \mu \mathrm{l})$. Continuous dynamic SPECT (acquisitions of 15-s each) was achieved over $30 \mathrm{~min}$ after iv injection of $600 \mu \mathrm{Ci}$ of ${ }^{99 \mathrm{~m}} \mathrm{Tc}-\mathrm{MAG} 3(n=3$ pairs $)$ or $200 \mu \mathrm{Ci}{ }^{123} \mathrm{I}-\beta_{2^{-}}$ microglobulin ( $n=3$ pairs), respectively. The linear motion of the detectors was set in such a way that the four-slit apertures would draw the narrowest rectangle possible around the animal. The distance between the actual contours and the collimator aperture was typically 
$\sim 3 \mathrm{~mm}$. The linear acquisition generates linograms forming a complete set of tomographic data allowing the reconstruction of the activity map (27).

Data processing. Reconstructions were performed using the maximum-likelihood expectation maximization algorithm with attenuation correction but without scatter correction or spatial resolution recovery (11). Time-activity curves were generated. ${ }^{99 m}$ Tc-MAG3 dynamic parameters were calculated using a three-compartment model, by fitting the curves to two exponentials.

The glomerular filtration rate (GFR) of ${ }^{123} \mathrm{I}-\beta_{2}$-microglobulin was assessed by fitting all the organ curves (heart, kidney, thyroid, liver, spleen, bladder) by a multicompartmental model (Supplemental Fig. 2). The GFR can be calculated as GFR $=k_{\mathrm{g}}^{1} \mathrm{~V}_{\mathrm{p}}(i)$, where $k_{\mathrm{g}}^{1}$ is the glomerular uptake rate of the ${ }^{123} \mathrm{I}-\beta_{2}$-microglobulin, and $\mathrm{V}_{\mathrm{p}}^{\mathrm{g}}$ is the plasma volume. Only the interval from 30 to $180 \mathrm{~s}$ postinjection was considered to avoid the effects of dilution after bolus injection, as well as ${ }^{123} \mathrm{I}-\beta_{2}$-microglobulin tubular reabsorption and metabolization, respectively. All kinetic parameters of renal uptake were calculated using SigmaPlot 2000 (Systat Software, Erkrath, Germany). The plasma volume of the mice was estimated based on blood volume (8\% body wt) (20) and 0.45 as average hematocrit value for the Clcn5 mice.

Autoradiography. For autoradiography, kidneys were exsanguined in situ, removed $7 \mathrm{~min}$ after iv injection of $620 \mathrm{ng} / \mathrm{g}$ of body weight of ${ }^{125} \mathrm{I}-\beta_{2}$-microglobulin, and fixed for $6 \mathrm{~h}$ at $4^{\circ} \mathrm{C}$ in $4 \%$ formaldehyde. Ten-micrometer sections were overlaid, treated with emulsion reagent (Ilford Scientific Product, Wilrijk, Belgium), and revealed after 1 mo.

Plasma and urine analyses. Urinary creatinine (modified Jaffé method) and albumin (turbimetric method) and plasma creatinine (enzymatic determination) were measured on a Synchron CX5 analyzer (Beckman Coulter, Brea, CA), following the manufacturer's protocols (3). The urinary excretion of the LMW Clara cell protein (CC16, $16 \mathrm{kDa}$ ) was measured by radioimmunoassay (7).

Statistics. Results are expressed as means \pm SD. Comparisons between $C l c n 5^{\mathrm{Y} /+}$ and $C l c n 5^{\mathrm{Y} /-}$ mice were made by Student's unpaired $t$-tests assuming equal variance. The significance level was set at $P<0.05$. Interassay variability was calculated as variation coefficient in 6 kidneys.

\section{RESULTS}

Imaging of the kidney cortex based on static ${ }^{99 m} T c-D M S A$ uptake. ${ }^{99 \mathrm{~m}} \mathrm{Tc}-\mathrm{DMSA}$ is regarded as the ideal tracer for cortical imaging of the kidney. After uptake through the basolateral membrane, ${ }^{99 m}$ Tc-DMSA remains firmly bound to PT cells. We first investigated the spatial resolution of ${ }^{99 \mathrm{~m}} \mathrm{Tc}-\mathrm{DMSA}$ SPECT imaging of the kidney in wild-type (C57) mice. At $5 \mathrm{~h}$ postinjection, ${ }^{99 \mathrm{~m}}$ Tc-DMSA SPECT clearly delineated the functional renal cortex, whereas the medulla and the pelvis area $(\sim 1 \mathrm{~mm})$ remained silent (Fig. $2 A)$. The tracer uptake was
A

Fig. 2. Single photon emission-computed tomography (SPECT) imaging of ${ }^{99 \mathrm{~m} T c-D M S A}$ in mouse: perfusion (kidney infarction) and functional (Clcn5 inactivation) defects. $A$ and $B:{ }^{99 \mathrm{~m}} \mathrm{Tc}$-DMSA SPECT $(A)$ in wild-type mice after apical infarction of the right kidney $(\mathrm{R})$. Coronal (top) and transverse (bottom) slices show no activity in the infarction area (arrowheads). Bars $=3 \mathrm{~mm}$. Histological examination after hematoxylin-eosin staining $(B)$ confirms the infarction of the top right pole of the corresponding kidney (low magnification, top; high magnification, bottom). Bars $=3 \mathrm{~mm}$ (top) and $100 \mu \mathrm{m}$ (bottom). C: kinetics of ${ }^{99 \mathrm{~m}} \mathrm{Tc}-\mathrm{DMSA}$ uptake in the kidney cortex measured using consecutive SPECT acquisitions ( $n=8$ kidneys from 4 mice). The asymptotic curve was fitted on the mean (red circle), and supports equilibrium ( $9.8 \pm 0.4 \%$ of injected dose) at 5 $\mathrm{h}$ postinjection in $\mathrm{Clcn} 5^{\mathrm{Y} /+}$ mice. SD is represented at each time point. Renal uptake of ${ }^{99 \mathrm{~m}} \mathrm{Tc}$-DMSA is abolished in $C l c n 5^{\mathrm{Y} /-}$ mice ( $n=8$ kidneys, blue square). $D$ and $E$ : representative coronal $(D)$ and transverse $(E)$ sections of ${ }^{99 \mathrm{~m}}$ Tc-DMSA SPECT imaging of $C l c n 5^{\mathrm{Y} /+}$ and $C l c n 5^{\mathrm{Y} /-}$ kidneys $(6 \mathrm{~h}$ postinjection), before and after furosemide administration $\left(10 \mathrm{mg} / \mathrm{kg}\right.$ body wt ip). In $C l c n 5^{\mathrm{Y} /+} \mathrm{kid}-$ neys, the tracer is concentrated over the cortex area and insensitive to furosemide administration. In $\mathrm{Clcn} 5^{\mathrm{Y} /-}$ mice, the ${ }^{99 \mathrm{~m}} \mathrm{Tc}-\mathrm{DMSA}$ signal is minimal, exclusively located in the pelvis, and rapidly cleared after furosemide injection. Dotted circles represent the cortical contours in Clcn $5^{\mathrm{Y} /-}$ kidneys. Bars $=3 \mathrm{~mm}$.

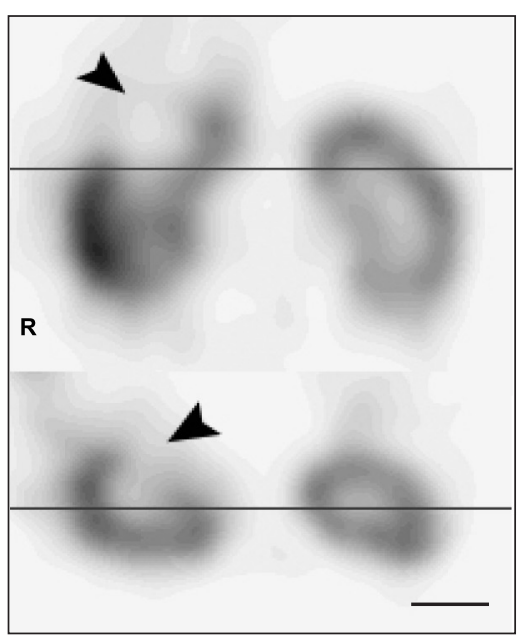

B

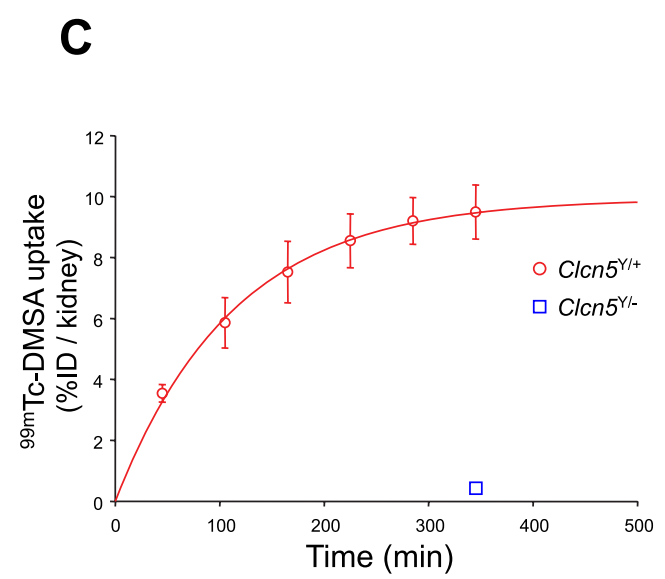

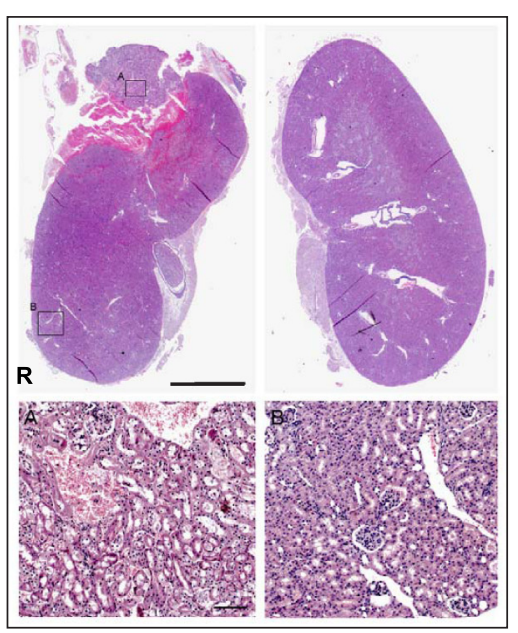

D

E

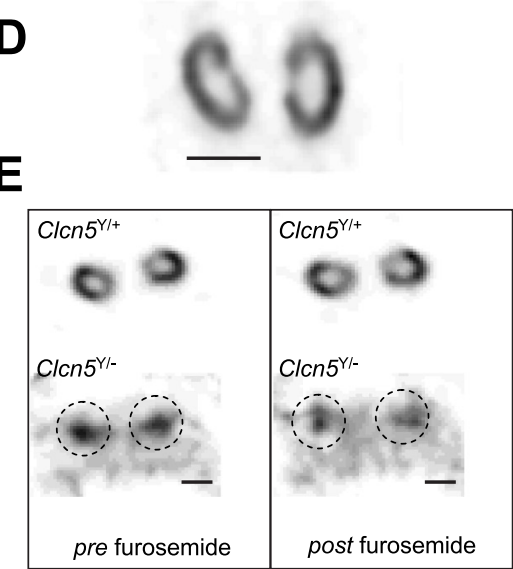


abolished over an apical area of experimental infarction, the boundaries of which correlated with the histopathological examination (Fig. 2, $A$ and $B$ ).

The kinetics of in vivo ${ }^{99 \mathrm{~m}} \mathrm{Tc}$-DMSA renal uptake in wild-type $\left(C l c n 5^{\mathrm{Y} /+}\right)$ mice increased progressively to a plateau level of $\sim 10 \%$ of the injected dose $5 \mathrm{~h}$ after injection (Fig. $2 C$; Table 1). The interassay variation coefficient $(5.6 \%)$ demonstrated highly reproducible uptake measurements. Coronal and transverse sections evidenced the accumulation of ${ }^{99 \mathrm{~m}} \mathrm{Tc}-\mathrm{DMSA}$ in the cortex of $C l c n 5^{\mathrm{Y} /+}$ kidneys, insensitive to furosemide (Fig. 2, D and $E$ ). In contrast, the cortical uptake of ${ }^{99 \mathrm{~m}} \mathrm{Tc}$-DMSA was abolished in $C l c n 5^{\mathrm{Y} /-}$ kidneys (Fig. 2, $C$ and $E$; Table 1), with minimal activity in the pelvis that was cleared after furosemide injection.

These results demonstrate that ${ }^{99 \mathrm{~m}} \mathrm{Tc}-\mathrm{DMSA}$ SPECT imaging is able to delineate the functional renal cortex in the mouse, with a $\sim 1$-mm spatial resolution and a kinetics of uptake similar to the asymptotic curve observed in humans. Defective ${ }^{99 \mathrm{~m}} \mathrm{Tc}$-DMSA cortical imaging is observed in cases of defective perfusion (kidney infarction) or generalized dysfunction of $\mathrm{PT}$ cells $\left(\mathrm{Clcn} 5^{\mathrm{Y} /-}\right.$ mice $)$.

Dynamic renography with ${ }^{99 m}$ Tc-MAG3. ${ }^{99 \mathrm{~m}} \mathrm{Tc}-\mathrm{MAG} 3$ is considered as the best tracer for dynamic imaging of the kidney. The tracer is concentrated in PT cells by basolateral uptake, followed by secretion into the urine without intracellular metabolization. The effect of anesthesia on the ${ }^{99 \mathrm{~m}} \mathrm{Tc}-$ MAG3 uptake by wild-type (C57) mice is shown on Fig. 3. Ketamine-xylazine anesthesia induced a significant delay in the ${ }^{99 \mathrm{~m}} \mathrm{Tc}-\mathrm{MAG} 3$ clearance, with a delayed and higher peak of uptake, as well as a higher degree of variability than in conscious mice. The dynamic renography in conscious $\mathrm{Clcn} 5$ mice is shown on Fig. 4.

The SPECT imaging of ${ }^{99 \mathrm{~m}}$ Tc-MAG3 handling by wild-type $C l c n 5^{\mathrm{Y} /+}$ kidneys is characterized by a rapid extraction from blood $\left(T_{1 / 2 \mathrm{IN}}, 0.4 \pm 0.1 \mathrm{~min}\right)$, maximal renal accumulation between 90 and $120 \mathrm{~s}$ after iv injection $(\sim 12 \%$ of injected dose/kidney), and subsequent tubular secretion ( $T_{1 / 2 \mathrm{OUT}}, 4.7 \pm$ $0.5 \mathrm{~min})$. Of note, the kinetic parameters of ${ }^{99 \mathrm{~m}} \mathrm{Tc}-\mathrm{MAG} 3$ handling are not significantly affected in $\mathrm{Clcn}^{\mathrm{Y} /-}$ mice (Fig. 4; Table 1).

Renal handling of ${ }^{123} I-\beta_{2}$-microglobulin in Clcn5 mice. $\beta_{2}$-microglobulin is a $12-\mathrm{kDa}$ protein that is ultrafiltrated and completely reabsorbed via receptor-mediated endocytosis at the apical pole of PT cells. Monitoring the endocytic uptake of

Table 1. Quantification by SPECT of proximal tubule functions in Clcn5 mice

\begin{tabular}{|c|c|c|c|c|}
\hline & $n$ & $\operatorname{Clcn} 5^{\mathrm{Y} /+}$ & $\operatorname{Clcn} 5^{\mathrm{Y} /-}$ & $P$ Value \\
\hline \multicolumn{5}{|l|}{${ }^{99 \mathrm{~m}} \mathrm{Tc}-\mathrm{DMSA}$} \\
\hline $\begin{array}{l}\text { Uptake, \%ID/kidney } \\
\text { 99mTc-MAG3 }\end{array}$ & 8 & $9.8 \pm 0.4$ & $0.4 \pm 0.1$ & $<0.01$ \\
\hline$T_{1 / 2 \mathrm{IN}}, \min$ & 6 & $0.4 \pm 0.1$ & $0.4 \pm 0.1$ & NS \\
\hline $\begin{array}{l}T_{1 / 2 \text { OUT }}, \text { min } \\
{ }^{123} \mathrm{I}-\beta_{2} \text {-microglobulin }\end{array}$ & 6 & $4.7 \pm 0.5$ & $4.2 \pm 1.2$ & NS \\
\hline$T_{\max }, \min$ & & {$[6.75 ; 7.25]$} & {$[1.75 ; 3]$} & $<0.01$ \\
\hline Uptake $_{7 \text { min }}, \%$ ID/kidney & 6 & $6.4 \pm 0.7$ & $0.5 \pm 0.2$ & $<0.01$ \\
\hline
\end{tabular}

Values are means \pm SD. $n$, No. of kidneys from 4 (3) pairs of Clcn 5 mice. SPECT, single proton emission-computed tomography; ${ }^{99 \mathrm{~m}} \mathrm{Tc}-\mathrm{DMSA},{ }^{99 \mathrm{~m}} \mathrm{TC}$ dimercaptosuccinic acid; \%ID, \% of injected dose; ${ }^{99 \mathrm{~m} T c-M A G 3,}{ }^{99 \mathrm{~m}} \mathrm{Tc}-$ mercaptoacetyltriglycine; $T_{1 / 2}$ IN , extraction from blood; $T_{1 / 2 \mathrm{OUT}}$, tubular secretion; $T_{\max }$, maximal renal accumulation; NS, not significant. Unpaired Student's $t$-test was used to compare $C l c n 5^{\mathrm{Y} /-}$ and $C l c n 5^{\mathrm{Y} /+}$ mice.

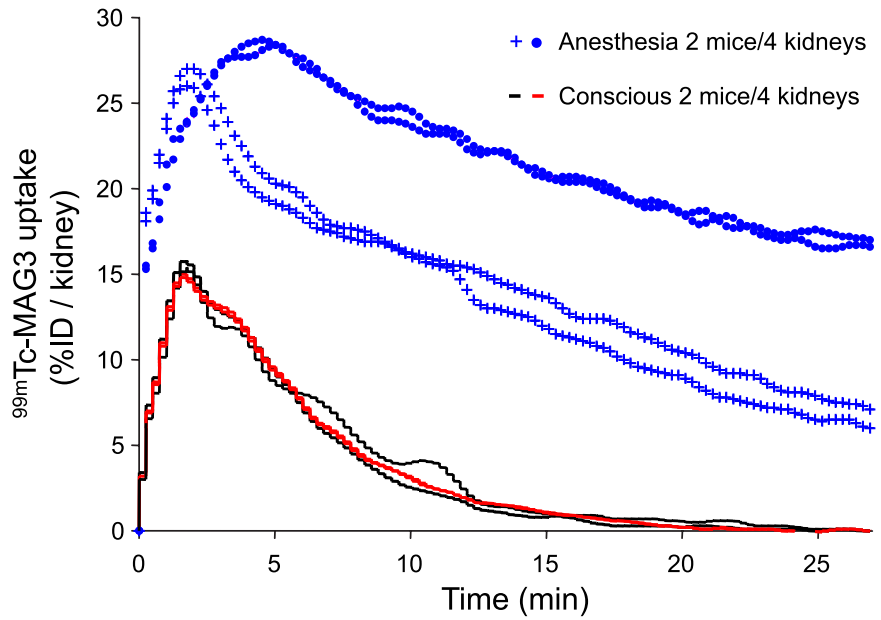

Fig. 3. Effect of anesthesia on ${ }^{99 \mathrm{~m}} \mathrm{Tc}-\mathrm{MAG} 3$ uptake in $\mathrm{C} 57$ mice. Dynamic SPECT imaging in 2 conscious mice (black and red lines matching the 4 kidneys) shows a rapid extraction of ${ }^{99}$ m Tc-MAG3 from blood ( $T_{1 / 2 \mathrm{IN}}, 0.4 \pm$ $0.1 \mathrm{~min})$, a maximal renal accumulation $120 \mathrm{~s}$ after iv injection $(\sim 15 \%$ of injected dose/kidney), and subsequent tubular secretion $\left(T_{1 / 2 \text { OUT }}, 3.1 \pm 0.3\right.$ min). Variability coefficients for $T_{1 / 2 \text { IN }}$ and $T_{1 / 2 \mathrm{OUT}}$ are 6.6 and $9.3 \%$, respectively. In contrast, ketamine-xylazine anesthesia in 2 mice (blue symbols for the 4 kidneys) induces a significant delay in ${ }^{99 \mathrm{~m} T c-M A G 3}$ clearance $\left(T_{1 / 2 \mathrm{OUT}}\right.$, $21.1 \pm 9.0 \mathrm{~min}$ ), as well as a higher variability for $T_{1 / 2 \mathrm{IN}}(54.0 \%)$ and $T_{1 / 2 \mathrm{OUT}}$ $(45.2 \%)$.

$\beta_{2}$-microglobulin is thus considered as a faithful marker of the activity of PT cells (7). The dynamic SPECT imaging of ${ }^{123} \mathrm{I}-\beta_{2}$-microglobulin handling by wild-type $\mathrm{Clcn} 5^{\mathrm{Y} /+}$ kidneys showed a rapid glomerular filtration followed by a progressive accumulation in the cortex, with maximal activity $(6.4 \pm 0.7 \%$ of injected dose/kidney) at 7 min postinjection (Fig. 5A; Table $1)$. The efficient breakdown of ${ }^{123} \mathrm{I}-\beta_{2}$-microglobulin in PT cells was reflected by ${ }^{123} \mathrm{I}$ reflux into the blood. The ${ }^{123} \mathrm{I}$

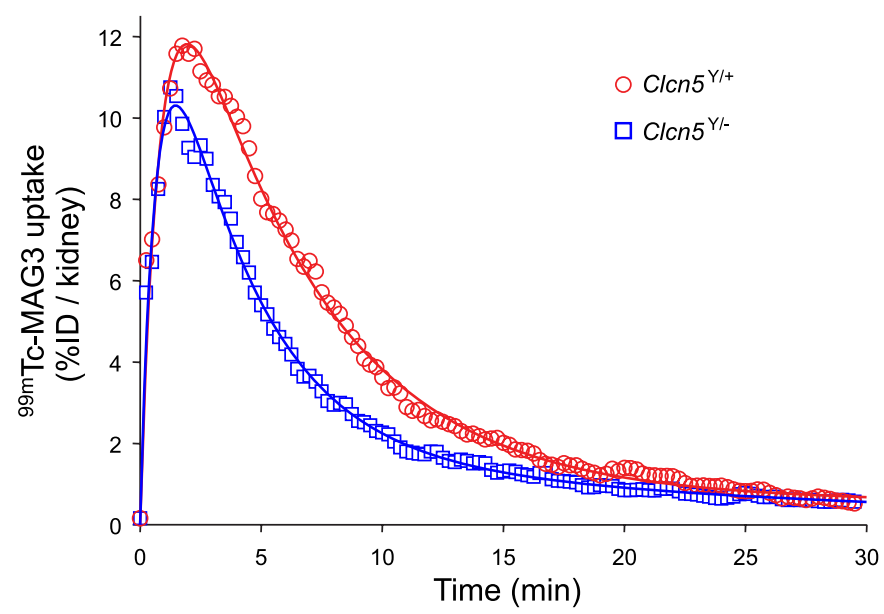

Fig. 4. Dynamic SPECT imaging of ${ }^{99 \mathrm{~m} T c-M A G 3}$ uptake in Clcn5 mice. The time-activity curve shows the rapid uptake of ${ }^{99 \mathrm{~m} T c-M A G 3}$ in the kidney cortex $\left(T_{1 / 2 \mathrm{IN}}, 0.4 \pm 0.1 \mathrm{~min}\right.$; variability coefficient, $\left.12.2 \%\right)$, resulting from the blood flow and the concentration by PT cells. The peak (maximal accumulation: $11.7 \pm 1.6 \%$ of injected dose/kidney) occurs between 90 and $120 \mathrm{~s}$ after iv injection, i.e., when excretion overcomes influx. The subsequent downsloping curve corresponds to the tubular secretion and elimination into the urine ( $T_{1 / 2 \mathrm{OUT}}, 4.7 \pm 0.5 \mathrm{~min}$; variability coefficient, $9.1 \% ; n=6$ kidneys from 3 pairs of $C l c n 5^{\mathrm{Y} /-}$ and $C l c n 5^{\mathrm{Y} /+}$ littermates). The spontaneous washout is slightly faster in $\mathrm{Clcn} 5^{\mathrm{Y} /-}$ mice (blue squares) than in wild-type $\mathrm{Clcn} 5^{\mathrm{Y} /+}$ mice (red circles). 


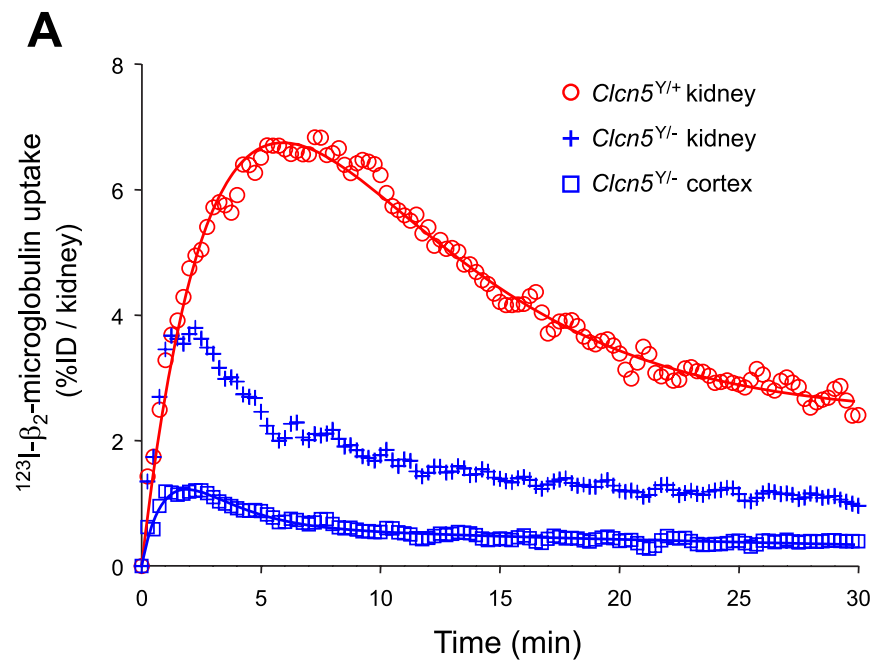

B
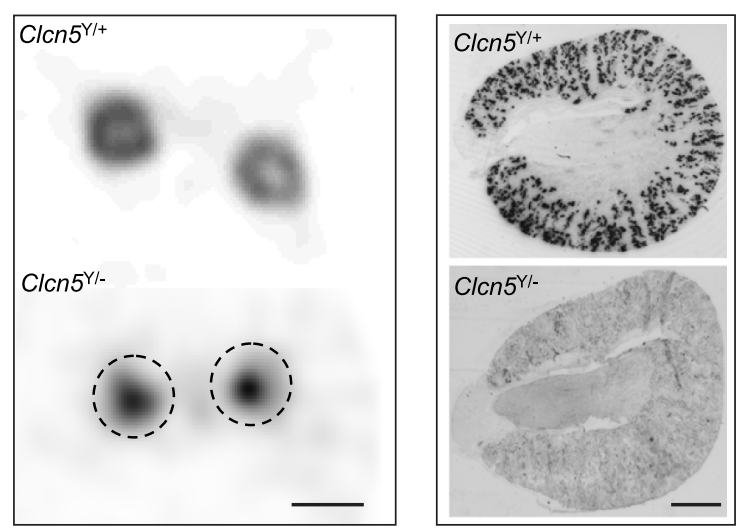

Fig. 5. Dynamic renal handling of $\beta_{2}$-microglobulin in Clcn5 mice. The time-activity curves show the progressive uptake of ${ }^{123} I-\beta_{2}$-microglobulin following glomerular filtration and apical, receptor-mediated endocytosis by PT cells. The first part of the ascending curve corresponds to the progressive accumulation of the tracer in the urinary lumen (i.e., glomerular filtration), whereas accumulation beyond the first 3 min corresponds to apical endocytosis by PT cells. A: dynamic SPECT analysis ${ }^{123} \mathrm{I}-\beta_{2}$-microglobulin in $\mathrm{Clcn} 5^{\mathrm{Y} /+}$ (red circle) and $C l c n 5^{\mathrm{Y} /-}$ (blue cross) whole kidneys, and $C l c n 5^{\mathrm{Y} /-}$ cortex (blue square). The curves show the average of 6 kidneys ( 3 pairs of mice) in each group. In $\mathrm{Clcn} 5^{\mathrm{Y} /+}$ mice, ${ }^{123} \mathrm{I}-\beta_{2}$-microglobulin rapidly accumulates in the cortex, with subsequent washout corresponding to breakdown and further release of free ${ }^{123} \mathrm{I}$ into the blood. In $\mathrm{Clcn}^{\mathrm{Y} /-}$ mice, ${ }^{123} \mathrm{I}-\beta_{2}$-microglobulin rapidly clears through the kidneys as a pure result of glomerular filtration. $B$ : representative distribution of iodine-labeled $\beta_{2}$-microglobulin in transverse kidney sections at $7 \mathrm{~min}$ postinjection in $\mathrm{Clcn}^{\mathrm{Y} /+}$ and $\mathrm{Clcn}^{\mathrm{Y} /-}$ mice: in vivo SPECT imaging vs. autoradiography. In $C l c n 5^{\mathrm{Y} /+}$ kidney, $\beta_{2}$-microglobulin is restricted to the cortex by SPECT, correlating with a segmental distribution along radial proximal tubules. In $C l c n 5^{\mathrm{Y} /-}$ mice, SPECT only detects activity in the pelvis without significant uptake in the cortex, as confirmed by the lack of autoradiographic signal. Dotted circles represent the cortical contours in $C l c n 5^{\mathrm{Y} /-}$ kidney. Bars $=5 \mathrm{~mm}$ (left) and $1 \mathrm{~mm}$ (right).

present in $\mathrm{Clcn} 5^{\mathrm{Y} /+}$ urine at $60 \mathrm{~min}$ postinjection was mostly free iodine ( $92 \pm 2 \%$ of total urine activity, $n=3$ ). In strong contrast, $\mathrm{Clcn} 5^{\mathrm{Y} /-}$ kidneys showed a severe defect in the reabsorption of ultrafiltrated ${ }^{123} \mathrm{I}-\beta_{2}$-microglobulin (Fig. $5 A$; Table 1), with predominant urinary loss of intact ${ }^{123} \mathrm{I}-\beta_{2}-$ microglobulin ( $62 \pm 4 \%$ of total urine activity, $n=3$ ). The autoradiography of kidneys fixed $7 \mathrm{~min}$ after injection of ${ }^{125} \mathrm{I}-\beta_{2}$-microglobulin, performed sequentially in the mice used for in vivo SPECT imaging, showed a strong cortical signal in
$C l c n 5^{\mathrm{Y} /+}$ kidneys contrasting with the lack of tracer uptake in $C l c n 5^{\mathrm{Y} /-}$ kidneys (Fig. 5B). Importantly, the calculated glomerular filtration rate of ${ }^{125} \mathrm{I}-\beta_{2}$-microglobulin $(0.22 \pm 0.02$ $\mathrm{ml} / \mathrm{min}$ ), based on the first part of the curve (see Fig. $5 A$ ), was similar in both strains of Clcn 5 mice. These data demonstrate that the congenital PT dysfunction caused by the lack of ClC-5 is adequately reflected by SPECT imaging of defective renal handling of $\beta_{2}$-microglobulin.

Renal uptake of ${ }^{123} I-\beta_{2}$-microglobulin: recovery after cisplatin injury. We used a model of reversible tubular toxicity induced by cisplatin, to test the potential of SPECT to provide a longitudinal assessment of acquired PT dysfunction in individual mice. The PT dysfunction, evidenced by the urinary excretion of albumin (and that of CC16, data not shown), peaked at day 5 and showed progressive recovery thereafter (Fig. 6A). A similar profile was observed by sequential SPECT

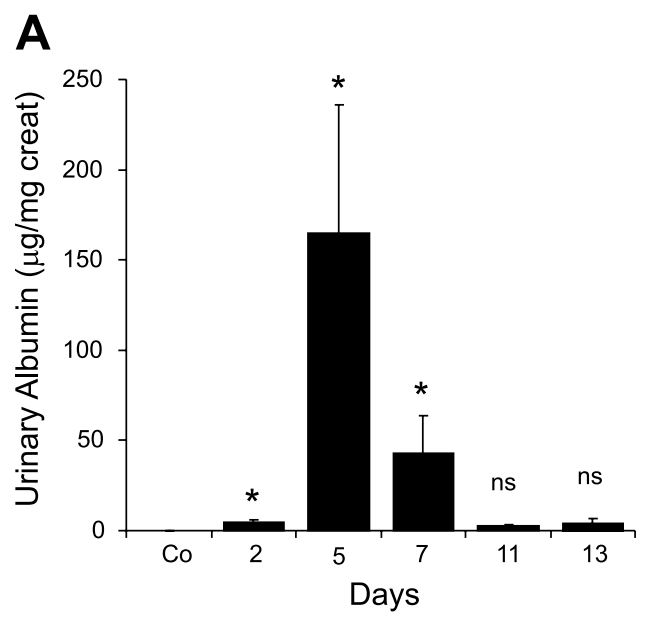

B

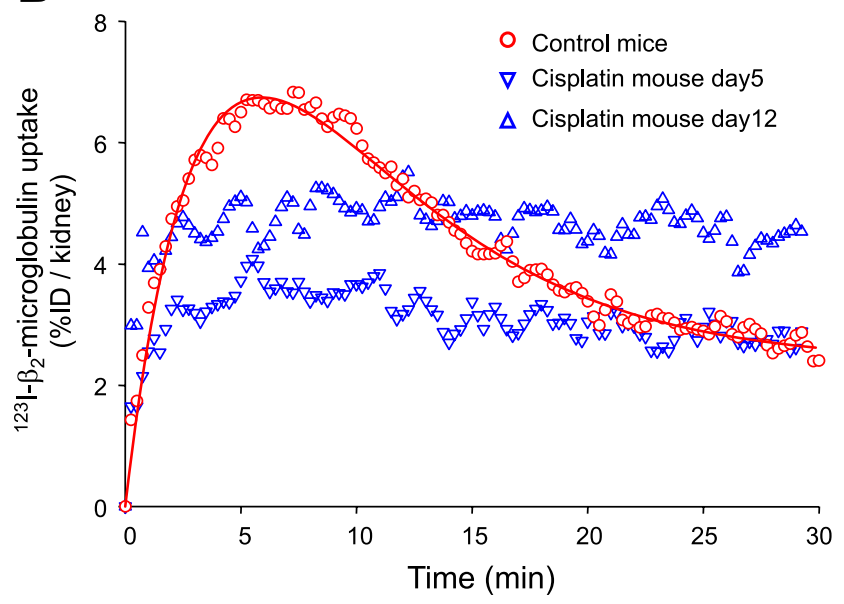

Fig. 6. Cisplatin-induced acute kidney injury: albuminuria and ${ }^{123} \mathrm{I}-\beta_{2}$-microglobulin handling. Shown are serial determination of the urinary excretion of albumin $(A)$ and repetitive SPECT imaging of ${ }^{123} \mathrm{I}-\beta_{2}$-microglobulin uptake in mice treated with cisplatin $(B)$. The urinary excretion of albumin (baseline: $0.06 \pm 0.04 \mu \mathrm{g} / \mathrm{mg}$ creatinine) peaked at day $5(165 \pm 70 \mu \mathrm{g} / \mathrm{mg}$ creatinine $)$ and subsequently decreased toward normal values at day $11(2.5 \pm 1 \mu \mathrm{g} / \mathrm{mg}$ creatinine) and day $13(3.8 \pm 3.2 \mu \mathrm{g} / \mathrm{mg}$ creatinine $)(* P<0.05$, at least 4 values/time point). ns, Not significant. Representative sequential SPECT imaging for ${ }^{123} \mathrm{I}-\beta_{2}$-microglobulin handling in control mice (red circle) and a cisplatin-treated mouse reveals defective endocytic uptake at day 5 (blue inverted triangle), with partial recovery at day 12 (blue triangle). Note that the excretion defect (curve $>7 \mathrm{~min}$ ) persists at day 12 . 
imaging for the renal uptake of ${ }^{123} \mathrm{I}-\beta_{2}$-microglobulin in individual mice, with a major defect of uptake at day 5 followed by partial recovery at day 12 (Fig. $6 B$ ).

\section{DISCUSSION}

This report demonstrates the feasibility and validity of both static and dynamic SPECT imaging to investigate specific PT functions in conscious mice. To the best of our knowledge, this is the first report of dynamic SPECT renography in conscious mice demonstrating the feasibility of continuous monitoring of drug handling from the time of iv injection.

Our studies of ${ }^{99 \mathrm{~m}} \mathrm{Tc}-\mathrm{MAG} 3$ showed a delayed tracer clearance and wider intra-assay variability in anesthetized mice, confirming the adverse impact of ketamine/xylazine on baseline renal function $(14,21,22,29)$. To circumvent the need for anesthesia, we used a simple plastic holder, which was sufficient to immobilize the mice without discomfort during SPECT acquisition (Supplemental Fig. 1). The imaging of conscious mice allowed us to sequentially use three radiotracers to assess distinct PT functions in the same mice: 1 ) uptake of ${ }^{99 \mathrm{~m}} \mathrm{Tc}-$ DMSA to evaluate the functional cortex with high resolution; 2) dynamic ${ }^{99 \mathrm{~m}} \mathrm{Tc}-\mathrm{MAG} 3 \mathrm{SPECT}$ to investigate the basolateral capture and apical secretion; and 3) processing of ${ }^{123} \mathrm{I}_{-} \beta_{2^{-}}$ microglobulin to assess apical receptor-mediated endocytosis. We took advantage of the $C l c n 5 \mathrm{KO}$ mice $(7,18,28)$ to provide a proof of concept for the use of SPECT, which showed a severe defect in both apical receptor-mediated endocytosis and basolateral anionic uptake, without significant alteration of the apical secretion by PT cells.

The renal uptake of ${ }^{99 \mathrm{~m}} \mathrm{Tc}-\mathrm{DMSA}$ showed a progressive accumulation in mouse kidney cortex, matching standard curves reported in humans (16). At the plateau phase, ${ }^{99 \mathrm{~m}} \mathrm{Tc}-$ DMSA SPECT yields a millimetric delineation of the cortex, sufficient to identify a local area of parenchymal damage, as documented by the experimental infarction model (Fig. 2, A and $B$ ). The procedure has a low interassay variability, which supports its usefulness for repetitive and long-term biodistribution studies, as well as longitudinal studies (e.g., evaluation of toxicity following treatment) in the same mice.

The dynamic SPECT quantification of $\beta_{2}$-microglobulin renal uptake provided the first in vivo time course of PT receptor-mediated endocytosis in conscious mice. The radiolabeled LMW protein is freely filtered by the glomeruli, avidly captured in the renal cortex, and rapidly degraded with subsequent release of the radiotracer and residual peptide/amino acids to peritubular capillaries (2). The compartmental analysis of ${ }^{123} \mathrm{I}-\beta_{2}$-microglobulin biodistribution (Supplemental Fig. 2) enabled us to determine a GFR of $0.22 \pm 0.02 \mathrm{ml} / \mathrm{min}$, similar to that reported previously by using FITC-inulin clearance (20). The usefulness of SPECT to evaluate PT function is further demonstrated by the Clcn5 $\mathrm{KO}$ mice, characterized by defective endocytosis due to the internalization of the multiligand receptors, megalin and cubilin $(7,18)$. Our data show that the defective PT apical endocytosis previously evidenced by ex vivo counting (7) is confirmed by noninvasive in vivo SPECT of ${ }^{123} \mathrm{I}-\beta_{2}$-microglobulin uptake. Despite similar GFR, the tubular reabsorption of ${ }^{123} \mathrm{I}-\beta_{2}$-microglobulin is strongly impaired in $C l c n 5^{\mathrm{Y} /-}$ mice, with altered metabolization in PT and subsequent loss in the urine, mostly as native ${ }^{123}$ I-labeled protein.
Similarly to $\beta_{2}$-microglobulin, the renal handling of ${ }^{99 \mathrm{~m}} \mathrm{Tc}$ DMSA has been regarded as an indicator of PT dysfunction in human and animal models $(1,25)$. For example, treatment of rats with Na-maleate induces a typical renal Fanconi syndrome, with marked reduction of ${ }^{99 \mathrm{~m}} \mathrm{Tc}-\mathrm{DMSA}$ uptake (19). In our study, SPECT quantification of ${ }^{99 \mathrm{~m}} \mathrm{Tc}-\mathrm{DMSA}$ capture shows that inactivation of $\mathrm{Clcn} 5$ is associated with a lack of tracer accumulation in the renal cortex, suggesting a severe defect in PT basolateral function. It is likely that the residual signal detected in the pelvis of $\mathrm{Clcn}^{\mathrm{Y} /-}$ mice represents a small glomerular filtration of ${ }^{99 \mathrm{~m}} \mathrm{Tc}$-DMSA (17). The basolateral uptake of ${ }^{99 \mathrm{~m}} \mathrm{Tc}-\mathrm{DMSA}$ from peritubular capillaries into S3 PT cells is mediated by the $\mathrm{Na}^{+}$/dicarboxylate cotransporter NaDC3 (SLC13A3) $(4,13)$ (Fig. 1). Of note, the coexpression of nonconducting fragments of $\mathrm{ClC}-5$ with $\mathrm{NaDC}$ transporters alters their translation and/or trafficking in Xenopus laevis oocytes, resulting in decreased surface expression (15). The severe deficit in both apical and basolateral SPECT uptake reported here further demonstrates that the functional loss of ClC-5 induces a generalized intracellular trafficking in PT cells $(7,18)$.

Renal scintigraphy with ${ }^{99 \mathrm{~m}} \mathrm{Tc}-\mathrm{MAG} 3$, a radiolabeled ana$\log$ of $p$-aminohippurate, can provide excellent image quality even with severe renal failure (10). For instance, ${ }^{99 \mathrm{~m}} \mathrm{Tc}-\mathrm{MAG} 3$ imaging detected changes in renal function in anesthetized mice as early as $5 \mathrm{~h}$ following ischemia-reperfusion injury (22). A model for ${ }^{99 \mathrm{~m}} \mathrm{Tc}-\mathrm{MAG} 3$ secretion by PT cells has recently been proposed, based on in vitro transport experiments in X. laevis oocytes (24) (Fig. 1). ${ }^{99 \mathrm{~m}} \mathrm{Tc}-\mathrm{MAG} 3$ is intracellularly accumulated through the basolateral organic anion transporter OAT1 that is expressed in all PT segments (4). The molecular counterpart of ${ }^{99 \mathrm{~m}} \mathrm{Tc}-\mathrm{MAG} 3$ apical transport could involve the $\mathrm{Na}^{+}$-dependent phosphate transporter NPT1 and/or the multidrug resistance protein $\operatorname{MRP} 2(5,24)$. Our results demonstrate that PT dysfunction caused by the functional loss of ClC-5 is not associated with a defect in ${ }^{99 \mathrm{~m}} \mathrm{Tc}-\mathrm{MAG} 3$ renal handling. The contrast between the complete loss of ${ }^{99 \mathrm{~m}} \mathrm{Tc}-$ DMSA basolateral uptake and the preserved ${ }^{99 \mathrm{~m}} \mathrm{Tc}-\mathrm{MAG} 3$ secretion in Clcn5 KO kidneys provides further evidence that these two pathways are functionally independent (24) and corroborates immunolocalization studies showing a distinct distribution of NaDC3 and OAT1 in PT segments (4). Additional SPECT studies using mouse models invalidated for distinct organic anion transporters may help establish the metabolic pathways handling these particular radiotracers, as well as other drugs and metabolites.

In conclusion, SPECT analysis represents a new approach to characterize the renal PT function in conscious mice, based on acute and/or repetitive biodistribution studies using distinct radiolabeled tracers. Two limitations cannot be ignored. First, the spatial resolution of SPECT, being limited to the millimetric range, cannot compete with rapidly evolving live-microscopy methods (6). Second, although SPECT offers a temporal resolution of 5-10 s for pharmacokinetic studies, this may not be sufficient to explore faster functions such as organelle activation or intracellular trafficking. Nevertheless, the development of creative approaches dedicated to small-animal imaging will permit further functional investigations of transgenic mouse strains, with relevance for renal physiology or disease mechanisms. 


\section{ACKNOWLEDGMENTS}

The authors thank H. Belge and M-F. van den Hove for helpful discussion; and V. Beaujean, Y. Cnops, M. De Bast, M. Helbo, Th. Lac, A. Saliez, and P. Van der Smissen for excellent technical assistance. The Clcn5 mice were kindly provided by W. B. Guggino and S. E. Guggino (Dept. of Physiology, Johns Hopkins University Medical School, Baltimore, MD).

\section{GRANTS}

F. Jouret was a Research Fellow of the Fonds de la Recherche Scientifique (FNRS). These studies were supported by the Belgian agencies FNRS and Fonds pour la Recherche Scientifique Médicale, the 'Fondation Alphonse and Jean Forton', a Concerted Research Action (05/10-328), an Inter-university Attraction Pole (IUAP P6/05), the DIANE project (Communauté Française de Belgique), and the EUNEFRON (FP7, GA 201590) program of the European Community.

\section{DISCLOSURES}

No conflicts of interest are declared by the authors.

\section{REFERENCES}

1. Anninga JK, Valdes Olmos RA, de Kraker J, van Tinteren H, Hoefnagel CA, van Royen EA. Technetium-99m dimercaptosuccinic acid and ifosfamide tubular dysfunction in children with cancer. Eur $J$ Nucl Med 21: 658-662, 1994.

2. Birn H, Christensen EI. Renal albumin absorption in physiology and pathology. Kidney Int 69: 440-449, 2006.

3. Biver S, Belge H, Bourgeois S, Van Vooren P, Nowik M, Scohy S, Houillier P, Szpirer J, Szpirer C, Wagner CA, Devuyst O, Marini AM. A role for Rhesus factor Rhcg in renal ammonium excretion and male fertility. Nature 456: 339-343, 2008.

4. Burckhardt BC, Burckhardt G. Transport of organic anions across the basolateral membrane of proximal tubule cells. Rev Physiol Biochem Pharmacol 146: 95-158, 2003.

5. Burckhardt G, Bahn A, Wolff NA. Molecular physiology of renal p-aminohippurate secretion. News Physiol Sci 16: 114-118, 2001.

6. Caplanusi A, Parreira KS, Lima WR, Marien B, Van Der Smissen P, de Diesbach P, Devuyst O, Courtoy PJ. Intravital multi-photon microscopy reveals several levels of heterogeneity in endocytic uptake by mouse renal proximal tubules. J Cell Mol Med 12: 351-354, 2008.

7. Christensen EI, Devuyst O, Dom G, Nielsen R, Van der Smissen P, Verroust P, Leruth M, Guggino WB, Courtoy PJ. Loss of chloride channel ClC-5 impairs endocytosis by defective trafficking of megalin and cubilin in kidney proximal tubules. Proc Natl Acad Sci USA 100: 84728477, 2003.

8. de Jong M, Barone R, Krenning E, Bernard B, Melis M, Visser T, Gekle M, Willnow TE, Walrand S, Jamar F, Pauwels S. Megalin is essential for renal proximal tubule reabsorption of (111)In-DTPA-octreotide. J Nucl Med 46: 1696-1700, 2005.

9. Hishikawa K, Marumo T, Miura S, Nakanishi A, Matsuzaki Y, Shibata K, Ichiyanagi T, Kohike H, Komori T, Takahashi I, Takase O, Imai N, Yoshikawa M, Inowa T, Hayashi M, Nakaki T, Nakauchi H, Okano H, Fujita T. Musculin/MyoR is expressed in kidney side population cells and can regulate their function. J Cell Biol 169: 921-928, 2005.

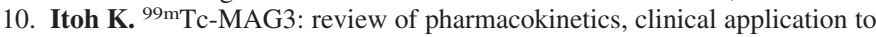
renal diseases and quantification of renal function. Ann Nucl Med 15: 179-190, 2001.
11. Lange K, Carson R. EM reconstruction algorithms for emission and transmission tomography. J Comput Assist Tomogr 8: 306-316, 1984.

12. Maisey M. Radionuclide renography: a review. Curr Opin Nephrol Hypertens 12: 649-652, 2003.

13. Markovich D, Murer H. The SLC13 gene family of sodium sulphate/ carboxylate cotransporters. Pflügers Arch 447: 594-602, 2004.

14. Mitchell SKI, Toal RL, Daniel GB, Rohrbach BW. Evaluation of renal hemodynamics in awake and isoflurane-anesthetized cats with pulse-wave Doppler and quantitative renal scintigraphy. Vet Radiol Ultrasound 39: 451-458, 1998.

15. Mo L, Wills NK. ClC-5 chloride channel alters expression of the epithelial sodium channel (ENaC). J Membr Biol 202: 21-37, 2004.

16. Moretti JL, Rapin JR, Saccavini JC, Lageron A, Le Poncin M, Bardy A. 2,3-Dimercaptosuccinic-acid chelates. 2. Renal localization. Int J Nucl Med Biol 11: 275-279, 1984.

17. Müller-Suur R, Gutsche HU. Tubular reabsorption of technetium-99mDMSA. J Nucl Med 36: 1654-1658, 1995.

18. Piwon N, Gunther W, Schwake M, Bosl MR, Jentsch TJ. ClC-5 Clchannel disruption impairs endocytosis in a mouse model for Dent's disease. Nature 408: 369-373, 2000.

19. Provoost AP, Van Aken M. Renal handling of technetium-99m DMSA in rats with proximal tubular dysfunction. J Nucl Med 26: 1063-1067, 1985.

20. Qi Z, Whitt I, Mehta A, Jin J, Zhao M, Harris RC, Fogo AB, Breyer MD. Serial determination of glomerular filtration rate in conscious mice using FITC-inulin clearance. Am J Physiol Renal Physiol 286: F590F596, 2004.

21. Rao S, Verkman AS. Analysis of organ physiology in transgenic mice. Am J Physiol Cell Physiol 279: C1-C18, 2000.

22. Roberts J, Chen B, Curtis LM, Agarwal A, Sanders PW, Zinn KR. Detection of early changes in renal function using ${ }^{99 \mathrm{~m}} \mathrm{Tc}-\mathrm{MAG} 3$ imaging in a murine model of ischemia-reperfusion injury. Am J Physiol Renal Physiol 293: F1408-F1412, 2007.

23. Rowland DJ, Cherry SR. Small-animal preclinical nuclear medicine instrumentation and methodology. Semin Nucl Med 38: 209-222, 2008.

24. Shikano N, Kanai Y, Kawai K, Ishikawa N, Endou H. Transport of ${ }^{99 \mathrm{~m}} \mathrm{Tc}-\mathrm{MAG} 3$ via rat renal organic anion transporter 1 . J Nucl Med 45: 80-85, 2004.

25. van Luijk WH, Ensing GJ, Meijer S, Donker AJ, Piers DA. Is the relative ${ }^{99 \mathrm{~m}} \mathrm{Tc}-\mathrm{DMSA}$ clearance a useful marker of proximal tubular dysfunction? Eur J Nucl Med 9: 439-442, 1984.

26. Walrand S, Jamar F, de Jong M, Pauwels S. Evaluation of novel whole-body high-resolution rodent SPECT (Linoview) based on direct acquisition of linogram projections. J Nucl Med 46: 1872-1880, 2005.

27. Walrand S, van Dulmen A, van Rossem H, Pauwels S. Acquisition of linograms in SPET: implementation and benefits. Eur J Nucl Med Mol Imaging 29: 1188-1197, 2002.

28. Wang SS, Devuyst O, Courtoy PJ, Wang XT, Wang H, Wang Y, Thakker RV, Guggino S, Guggino WB. Mice lacking renal chloride channel, CLC-5, are a model for Dent's disease, a nephrolithiasis disorder associated with defective receptor-mediated endocytosis. Hum Mol Genet 9: 2937-2945, 2000.

29. Yang XP, Liu YH, Rhaleb NE, Kurihara N, Kim HE, Carretero OA. Echocardiographic assessment of cardiac function in conscious and anesthetized mice. Am J Physiol Heart Circ Physiol 277: H1967H1974, 1999. 